\title{
A PROMOÇÁO DA SUSTENTABILIDADE SOCIAL NA SOCIEDADE TRANSNACIONALIZADA A PARTIR DA NORMA ISO 26.000
}

\author{
Márcio Ricardo Staffen ${ }^{1}$ \\ Universidade do Vale do Itajaí (UNIVALI) \\ Gustavo Polis ${ }^{2}$ \\ Faculdade Meridional (IMED)
}

\section{Resumo}

O presente trabalho propóe uma reflexão aprofundada acerca do modo pelo qual é possível promover o ideal da sustentabilidade em face a um mundo largamente pautado pelo fenômeno da globalização. Em razão disso, observa-se como problema central de pesquisa, como os expedientes de standards, como a ISO 26.000, podem ser ferramentas úteis para a promoçâo da sustentabilidade social. A hipótese de pesquisa ofertada como possível resposta ao problema apresentado é a de que ferramentas aos moldes da ISO 26.000 são capazes de disseminar as práticas de sustentabilidade em escala transnacional a partir da maior utilização por parte dos atores envolvidos de vias e instrumentos alternativos de regulação, como a os standards. O método utilizado é o hipotético-dedutivo, baseado em pesquisas e análises bibliográficas.

Palavras-chave: ISO 26.000; standards; sustentabilidade social; transnacionalismo.

1 Doutor em Direito Público pela Università degli Studi di Perugia. Doutor e Mestre em Ciência Jurídica pela UNIVALI. Estágio de Pós-doutorado em Direito junto à Università degli Studi di Perugia (Bolsa CAPES/PDE 88881.120155/2016.1). Graduado em Direito pela UNIVALI. Pesquisador do Conselho Nacional de Justiça (CNJ). Professor Permanente no Programa de Pós-graduaçáo stricto sensu em Ciência Jurídica (Mestrado e Doutorado) na UNIVALI (Conceito CAPES 6). Advogado (OAB/SC). Membro da Comissão de Direitos Humanos (OAB/SC). Membro da Comisión de Derechos Humanos del Estado de México (México). Membro do Comite da Escuela de Formación de Auxiliares Jurisdiccionales de la Corte Superior de Justicia del Callao (Peru). Membro Honorário do Ilustre Colegio de Abogados de Ancash (Peru). Membro efetivo da Sociedade Literária Săo Bento. Membro do Conselho Nacional de Pesquisa e Pós-graduação em Direito - CONPEDI. Membro do Grupo de Pesquisa Transnacionalismo e Circulação de Modelos Jurídicos (PPGD-IMED). Líder do Centro de Estudos sobre Direito e Transnacionalidade (UNIVALI). ORCID: https://orcid.org/0000-0002-4072-2644 / e-mail: marcio. staffen@imed.edu.br

2 Mestrando em Direito pela IMED. Graduado em Direito pela IMED. Bolsista CAPES/PROSUP. Bolsista de iniciação científica PROBIC/FAPERGS (2016/2017 e 2017/2018). Membro dos grupos de pesquisa "Transnacionalismo e Circulação de Modelos Jurídicos" e "Ética, Cidadania e Sustentabilidade”. Advogado (OAB/RS). E-mail: polis.g@outlook.com 


\section{PROMOTING SOCIAL SUSTAINABILITY IN THE TRANSNATIONALIZED SOCIETY FROM ISO 26.000 NORM}

\section{Abstract}

The present work seeks to propose an indepth reflection on the way in which it is possible to promote the ideal of social sustainability in the face of a world largely guided by the globalization phenomenon. As a result, it is observed as a central research problem: Can the standards files, such as ISO 26.000, be useful tools for the promotion of social sustainability? The research hypothesis offered as a possible answer to the problem presented is that tools along the lines of ISO 26.000 are capable of disseminating social sustainability practices on a transnational scale. Through the hypothetical-deductive method, based on research and bibliographic analysis, the general objective is to analyze the possibility of promoting the implementation of social sustainability practices at the transnational level based on the greater use by transnational actors of alternative ways and regulation instruments, such as the use of standards, like the ISO 26.000 norm.

Keywords: ISO 26.000; social sustainability; standards; transnationalism. 


\section{Introdução}

A partir do século XX, especialmente após os eventos de 1945, a sociedade classicamente reconhecida em associação ao Estado Moderno iniciou um processo de descolamento dessa definição. Com a intensificação dos movimentos de globalização e, posteriormente de transnacionalização, a face social dos países e de suas relaçóes de poder, especialmente para com a sociedade civil, foi largamente alterada e, portanto, as demandas sociais destes novos tempos não são mais aquelas enfrentadas durante a modernidade.

O empoderamento das instituiçóes privadas transnacionais durante o período supracitado gerou uma série de complicaçôes sociais com as quais, até o presente momento histórico, o Estado não havia se deparado. Em especial, nesse contexto, emergiu uma crescente preocupação com a possibilidade de efetivação da ideia de sustentabilidade em seu viés social nas diferentes demandas do dia a dia, tema caro na sociedade do século XXI, pautado por fortes movimentos de transnacionalização.

Neste cenário de instabilidade e, principalmente, de incerteza, questiona-se acerca da capacidade dos Estados em resolver os problemas característicos da globalização com seus meios clássicos, e surge a iniciativa de cooperação entre os atores públicos e os novos atores privados transnacionais para a resolução dessas novas demandas. Há cada vez mais normas standards, elaboradas por instituiçóes híbridas (não puramente estatais e, por vezes, totalmente privadas), que são utilizadas como balizadores e norteadores das atividades de organizaçóes públicas e privadas no trato das questóes mais importantes de nosso tempo, como é o caso da norma ISO 26.000, concernente à responsabilidade social nas atividades empresariais transnacionais.

Por essa razão, o presente trabalho trata do modo pelo qual é possível promover a sustentabilidade no mundo globalizado. O problema de pesquisa apresentado é: os expedientes de standards, como a ISO 26.000, podem ser ferramentas úteis para a promoção da sustentabilidade? A hipótese de pesquisa, portanto, é que as ferramentas aos moldes da ISO 26.000 são capazes de disseminar a sustentabilidade social em escala transnacional. Por meio do método hipotético-dedutivo, e tem-se como objetivo geral analisar a possibilidade de fomento e implementação de tais práticas.

Para perseguir o objetivo proposto, subdividiu-se o trabalho em três tópicos: (1) no primeiro, será abordada a questão da proliferação da transnacionalidade e, com isso, o empoderamento dos atores nesse processo; (2) no segundo momento, serão demonstradas as problemáticas decorrentes da atuação de transnacionais e, a título exemplificativo, o caso Chevron x Equador será, para demonstrar as 
dificuldades dessas novas relaçóes; e (3) por último, a questão da sustentabilidade em sua dimensão será abordada, bem como uma reflexão sobre sua aplicabilidade, em especial, a partir da utilização de expedientes como a norma ISO 26.000.

\section{A transnacionalidade e os novos atores transnacionais}

Durante toda a fase seguinte à chamada Paz de Westfalia, o Direito foi progressivamente visto como um aparato tipicamente estatal, exclusivamente oriundo deste, cujo monopólio da força encontrava o fundamento da soberania (CRUZ; OLIVIERO, 2013, p. 33). Todavia, a confecçáo jurídica, na era da globalizaçáo, busca transformar esse paradigma ao propor um esquema, de certo modo, relacional, até então desconhecido, tendo como ponto fundamental a centralidade do indivíduo como entidade liberta das relaçôes comunitárias, fazendo que o órgão judicial perca seu caráter de territorialidade.

Entretanto, mais do que falar em uma suposta superação do direito estatal, é preferível falar na transformação deste, a qual encontra explicação na hegemonia exercida, em especial, pelo fator econômico no âmbito jurídico (CRUZ; OLIVIERO, 2013, p. 33). Deve-se ter em mente a existência e relevância de novos tipos de poder transnacionais que não são limitados pelos moldes clássicos da teoria jurídica.

Com a proliferação do fenômeno da globalização, espaços de debilidade passaram a ser ocupados, sobretudo após a Segunda Guerra Mundial, por uma agenda de interesses constituída por meio de instituiçôes novas, de difícil caracterização à luz do glossário político-jurídico da modernidade. A homogeneidade tradicional no pensamento político e jurídico fora intensamente perdidas, e instalou-se um cenário de grande tensão institucional, em que o Estado e os indivíduos depararam-se com uma sensação de profunda insegurança (STAFFEN, 2015, p. 34).

Por assim dizer, a força motriz do Direito não mais são anseios de limitaçáa jurídica dos poderes estatais absolutos. A função do Direito, em tempos de globalização e transnacionalização, está associada diretamente pela regulação de dinâmicas policêntricas atreladas com a circulação de modelos, capitais, pessoas e instituiçôes distribuídos tanto em espaços físicos como nos virtuais.

Nesse contexto, a capacidade de o ente estatal produzir, soberanamente, os sistemas jurídicos nacionais vem, paulatinamente, diminuindo. Isso ocorre, em grande parte, porque as próprias opçóes políticas abertas às maiorias parlamentares encontram-se reduzidas a uma constante concessão de soberania à comunidade transnacional, principalmente por meio de instituiçôes como o Fundo Monetário 
Internacional, a Troika, a ONU e suas agências, bem como as grandes corporaçôes transnacionais que criam uma espécie de estado de necessidade econômica, a partir do exercício de seus tentáculos de influência (CRUZ; OLIVIERO, 2013, p. 34), redefinindo, portanto, o cerne da capacidade legislativa do Estado.

Depois de longas discussóes acadêmicas acerca do papel da sociedade civil, assentou-se que esse fenômeno é a expressão de uma contraposição na dicotomia estabelecida entre Estado e sociedade civil. Durante o transcorrer da década de 1970, principalmente na Europa, esta discussão realocou-se a partir da fusão das esferas políticas e não políticas da vida social (ARNAUD, 2007, p. 225), muito em função da crescente participação do chamado terceiro setor e das empresas transnacionais na esfera de influência da regulaçáo.

Nesse sentido, outra questáo de fundamental importância é saber se o setor privado, especialmente as empresas, integram ou não a sociedade civil. Há, ainda, correntes distintas acerca da temática, na medida em que as empresas, diferentemente das ONGs, por exemplo, têm como principal finalidade a geração de lucro. Porém, a gratuidade náo pode ser considerada um critério absoluto para a integração à sociedade civil, haja vista que os orçamentos têm um volume significativo representado pelo capital privado, que se faz necessários à sociedade, inclusive para que possam implementar programas sociais (ARNAUD, 2007, p. 231).

[...] empresas privadas, em número cada vez maior, gostariam de juntar-se aos objetivos de um certo número de movimentos da sociedade civil. No que diz respeito ao desenvolvimento sustentável, por exemplo, algumas empresas, já o mencionamos, chegam até a qualificar-se como "eco-empresas cidadâs" (ARNAUD, 2007, p. 231).

Independentemente do que se possa pensar acerca do enquadramento das empresas de caráter transnacional como membros da sociedade civil, o que se verifica é o aumento de seu grau de influência. Assim, deve-se desenvolver práticas para que essas instituiçóes também entrem no arco de atenção do direito.

Como já demonstrado, a interação de diferentes atores na vida pública e privada no âmbito da sociedade sem fronteiras é deveras intensa. Todos esses agentes (ONGs, empresas, companhias e o próprio Estado) existem inseridos em um mesmo contexto cultural, filosófico e econômico, pautados por valores e regras que compartilham entre si, em uma espécie de cooperação global (partnership) (BRASIL, 2001, p. 38).

Insta salientar que grande parcela do mérito para a confecção desse network se deve ao profundo desenvolvimento científico e tecnológico característicos da 
segunda metade do século XX, ao passo em que encurtaram as distâncias do globo terrestre, fomentando o intercâmbio cultural em todos os níveis (BRASIL, 2001, p. 40). Essa transformação desenvolveu-se e propagou-se como uma rede de nós rígidos e malha elástica, em que cada espectro está em interaçáo com os demais, por exemplo, o progresso tecnológico permitiu, e permite, uma melhor organização das fábricas, e essas, por sua vez, aceleram o processo tecnológico.

Ao disseminar seus diversos bens e serviços além das fronteiras do país onde iniciaram suas atividades, as empresas transnacionais inauguraram uma economia global, independente de pressóes estatais, pautada com grande influência de correntes privadas (RADU, 2009, p. 399), de modo que seus agentes, a exemplo dos bancos, organizaçôes internacionais e agências reguladoras, se tornarão os atores protagonistas desse cenário global.

Pode-se anunciar alguns exemplos para ilustrar esse novo palco de cooperação oriundo da mudança de paradigma global. Composto por organismos de normatização de matriz híbrida público-privada, a Organização Internacional para a Normatização (ISO) tem criado pontes entre setores públicos e privados, mas, com atribuiçôes de cunho regulamentar iminentemente públicas (STAFFEN, 2015, p. 28).

Caso similar é o ocorrido quando da aderência de diversos Estados ao Comitê da Basileia, entidade de caráter nacional, com finalidade de regimentar as atividades bancárias a níveis mundiais. Ainda, como maior expoente desse tipo de relação, observa-se o caso do regimento da internet, cuja responsabilidade de regular o uso da ferramenta encontra-se no escritório de uma empresa público-privada - a Internet Corporation for Assigned Names (ICANN) - que acaba por prestar um serviço público destinado a todo o globo (STAFFEN, 2015, p. 28).

Nessa mesma linha, há instituiçóes exclusivamente privadas que transitam com frequência nesse espaço mundial, cujas relaçóes de dependência em relação aos entes públicos e estatais é, de fato, inexistente. Possivelmente os maiores exemplares desse formato de instituição sejam a Federação Internacional de Futebol Associado (FIFA) e da Câmara Internacional do Comércio (ICC), as quais desenvolvem seus trabalhos de maneira completamente autônoma, inclusive elaborando normas acerca daquilo que lhes é de interesse, com o fito central de promover o comércio e demais investimentos internacionais; para isso, fazem-se parceiras importantes de organismos nacionais, internacionais e transnacionais (STAFFEN, 2015, p. 29), influenciando cada uma dessas instituiçóes e seu modo de conveniência.

Não sem razão, depreende-se do atual contexto que a governança global vai muito além da elaboração de leis e do estabelecimento das diferentes modalidades de regras. Aos olhos do indiano, especialista em relaçóes internacionais, Para Khanna, esse ambiente de caos pode encontrar alguma ordem no desenvolvimento 
de uma megadiplomacia (KHANNA, 2011, p. 33), a qual deve buscar o apaziguamento entre os diferentes atores da arena mundial, destrancando, assim, recursos de ONGs, corporaçôes e instituiçóes transnacionais, bem como de governos para que esses atuem em um mesmo sentido, possibilitando a realizaçáo de empreendimentos conjuntos, capazes de fazer frente às questóes resultantes do estabelecimento de uma comunidade transnacionalizada.

O extenso processo de transferência de poder das economias nacionais para o livre mercado, pautado pelos mercados globais, pode ser classificado como a mudança mais importante ocorrida no século XX, devido ao poder e a influência das empresas e organismos de caráter transnacional, assim como pelo advento das networks, nas quais operam em escala mundial (RADU, 2009, p. 402).

Consequentemente, é perceptível a proliferação de instituições privadas envolvidas no trato de assuntos que dizem respeito à regulação de assuntos globais nos mais diversos campos, como a proteção e promoçáo da sustentabilidade em suas diversas formas, do direito à alimentação, da tutela da propriedade intelectual e outros tantos.

No que concerne especificamente às empresas transnacionais, estas pautam sua atuação como players globais a partir do uso de sua força expansionista econômica, suas próprias regras de funcionamento e estratégias, mesmo que em detrimento daquilo que é de interesse público para o país onde desenvolvem suas atividades. Com o intuito de preservarem os investimentos externos, os países são forçados a fazer concessões, em alguns casos, até mesmo prejudiciais a suas economias, favorecendo os desígnios das empresas transnacionais (RADU, 2009, p. 400).

Levando em conta a grande instabilidade causada pela atuação dessas instituiçôes de caráter transnacional no aparato social clássico, novas discussôes e temas de reflexão paulatinamente começam a granjear espaço. Uma dessas discussóes é sobre a promoção da ideia de sustentabilidade e, em especial, o conceito de sustentabilidade social. Em razão disso, o tópico seguinte irá traçar algumas consideraçóes importantes sobre a temática.

\section{A problemática do empoderamento irrefreado das empresas transnacionais: o caso Chevron $\times$ Equador}

Como anteriormente colacionado, corpos privados vêm ganhando força e espaço dentro dos territórios nacionais, em especial, desde findado o segundo período pós-guerra. Um modelo desse espécime de relação pode ser extraído do estudo de caso da relaçáo entre a companhia Chevron/Texaco e o governo do Equador durante os anos de 1960 até meados da década de 1990. 
A extração de petróleo é considerada uma intensa atividade industrial, eis que, entre outros impactos, gera uma vasta quantidade de dejetos tóxicos, bem como apresenta o permanente risco de vazamentos (KIMERLING, 2013, p. 242). O consórcio liderado pela Chevron/Texaco, nos dias atuais conhecida apenas como Chevron, extraiu aproximadamente 1.5 bilhóes de barris de petróleo bruto na regiấo da Amazônia equatoriana durante um período de 28 anos, de 1964 até 1992.

Durante as operaçóes da Chevron/Texaco no Equador, rotineiramente a empresa despejava o petróleo cru nas estradas que circundavam suas instalaçôes, com o intuito de controlar a poeira e realizar sua manutenção. Na mesma linha, descartava toneladas de diversos tipos de lixo tóxico no ambiente, cuja consequência foi a contaminação de rios e seus respectivos afluentes, que serviam como fonte direta de alimento e água potável para as comunidades locais. Somando-se a esses fatos, percebia-se que vazamentos nos tubos de extração dispersavam óleo no meio ambiente (KIMERLING, 2013, p. 243), ao passo que se estima o despejo de 19 milhóes de galóes de petróleo bruto na bacia amazônica durante o período.

Ressalte-se que o caso ganhou notoriedade somente no ano de 1993, com o ajuizamento de uma ação judicial na cidade de Nova Iorque. No processo, os povos indígenas e outros assentamentos comunitários da regiáo, correspondente à área explorada pelas atividades da empresa no Equador, reclamaram os danos a eles impostos pela degradação ambiental criada pela Chevron/Texaco.

Outro aspecto que pede atenção quando da análise do caso em tela é a atuação conjunta do governo equatoriano e da Chevron/Texaco na neutralização do domínio do povo Huaorani sobre as terras da bacia amazônica no Equador. Por meio da influência de dirigentes dentro do governo do Equador, o ente público passou a implementar uma agressiva política de colonização interna (KIMERLING, 2013, p. 264), oferecendo títulos de propriedade e fácil acesso a crédito para cidadãos de outras áreas do país que migrassem para a Amazônia, e limpassem a floresta, preparando os terrenos para o plantio, e auxiliando no processo de civilizar do povo Huaorani e outros nativos, com a finalidade de viabilizar as atividades industriais na área.

Ainda, mais de 200 membros da tribo Huaorani foram pressionados a deixar suas terras e ir viver em um distante assentamento cristáo (KIMERLING, 2013, p. 268). Aqueles que se recusaram a mudar sua residência, foram despojados de grande parte de seus territórios pelos novos fazendeiros.

Em função disso, aqueles que se sentiram lesados pela atuação da empresa, unidos em uma espécie de associação, passaram a buscar a reparação de danos em juízo. Essa demanda tornou-se, para a discussão acerca da aplicação do direito em 
nível transnacional, um caso de estudo na medida em que releva as complexidades dos litígios envolvendo atores estatais e privados em conexão com diferentes Estados Nacionais (WHYTOCK, 2012, p. 425).

O caso Chevron/Equador tem conexôes tanto com os Estados Unidos, quanto com o Equador, o que ocasionou diversas dificuldades no que diz respeito à escolha do foro competente, da legislação aplicável ao caso e aos efeitos de decisóes proferidas por um tribunal estrangeiro dentro do território nacional de outro país. Tais questôes não são necessariamente uma novidade, porém, a litigância transnacional tem se tornado cada vez mais multipolar, de modo a tornar esses contenciosos ainda mais complexos (WHYTOCK, 2012, p. 425).

Os residentes equatorianos que tiveram suas vidas modificadas em razão das atividades da empresa incialmente ajuizaram uma ação por reparação de danos nos Estados Unidos, local da sede da empresa Chevron. Outrossim, a justiça americana julgou a referida ação improcedente, alegando a incompetência da jurisdição para o julgamento de mérito, haja vista os fatos descritos pelos autores terem ocorrido em território estrangeiro. Em momento posterior, os reclamantes ajuizaram nova demanda no Equador (WHYTOCK, 2012, p. 425). Desta vez, a empresa fora condenada a pagar, a título de indenização, U\$\$ 9,5 bilhóes de dólares para os moradores da região onde realizava suas operações, em função dos danos ambientais causados e seus desdobramentos às populaçóes locais.

Em que pese a condenação junto a justiça equatoriana, a empresa Chevron promoveu um recurso contra a referida decisão junto ao Tribunal Permanente de Arbitragem, em Haia, na Holanda. O recurso foi baseado na alegação por parte da petroquímica de que o advogado representante dos grupos de moradores da Amazônia equatoriana supostamente teria prometido determinado valor em dinheiro para um juiz equatoriano, em troca de que fosse permitido redigir alguns trechos da sentença ${ }^{3}$.

Ao final, o Tribunal Internacional decidiu favoravelmente à companhia Chevron/Texaco, entendendo que a justiça do Equador haveria denegado a justiça no caso. Em razão desse julgamento, foram desfavorecidos mais de trinta mil moradores da regiáo equatoriana onde a Chevron/Texaco havia despejado quantidade significativa de resíduos tóxicos, que contaminaram aqueles territórios, bem como uma série de nascentes dos rios da região.

3 Nesse caso particular, é importante frisar que "O Tribunal Permanente de Arbitragem, em Haia, anulou uma condenação de 9,5 bilhóes de dólares contra a petroquímica Chevron, destruindo a pretensão de cidadãos da Amazônia de receber indenizaçōes da multinacional por danos ao meio ambiente. A decisão emitida pelo tribunal determina que "o Equador é responsável por denegação de Justiça e lhe ordena a anulação da sentença", anunciou a Procuradoria equatoriana nesta sexta-feira. O órgão, que atua como advogado do Estado equatoriano, acrescentou que ainda poderá recorrer da decisão de primeira “instância”. O GLOBO. Rio de Janeiro, 07 set. 2018. Disponível em: https:// oglobo.globo.com/sociedade/corte-internacional-anula-condenacao-milionaria-da-chevron-no-equador-23050629. Acesso em: 13 ago. 2019. 
Outro aspecto importante que emergiu do caso envolvendo a empresa Chevron e o Equador são suas características jurídicas únicas. $\mathrm{O}$ processo judicial envolvendo as duas partes foi além das jurisdiçôes nacionais do Equador e dos Estados Unidos da América, perpassou, igualmente, um processo de arbitragem de matriz privada e um sistema de proteção de direitos humanos regional, o que ilustra com muita precisão aquilo que se denomina complexidade entre sistemas e entre Estados, ou seja, a complexidade que emerge quando uma disputa jurídica envolve mais do que um sistema jurídico nacional e/ou internacional (WHYTOCK, 2012, p. 426).

Tomando-se para análise o caso Chevron/Texaco, há que se observar uma pertinente característica presente no transnacionalismo. A atuação do mercado, enquanto processo de operação desimpedida, se estabelece em dois polos. Tem-se, por um lado, que o interesse de um grupo de pessoas pode ser atendido graças à liberdade de funcionamento do mercado, e por consequência, esse grupo, se politicamente influente, procederá com a realização de açóes que busquem dar ao mercado ainda mais espaço na economia. Quando essa condição ocorre, observa-se o afastamento - para não fazer uso do termo renúncia - da ética empresarial ${ }^{4}$ (SEN, 2010, p. 162-163).

Sob outra perspectiva, a igual atuação desregrada do mercado é fator decisivo para que os interesses de outros grupos de indivíduos sejam prejudicados ou impedidos de ser alcançados (SEN, 2010, p. 162). Considerando-se que essas pessoas podem não exercer influência e/ou não dispor de poder político, há de se reconhecer uma vulnerabilidade latente.

As preocupaçôes apresentadas por Sen sobre o desempenho da atividade desses novos atores transnacionais também se refere às consequências sociais. Para o autor - que tece seu pensamento em diálogo com os escritos de Adam Smith -, há uma grande perda social envolvida nos processos de produção privada, por exemplo, com a poluição e o desperdício ambiental - ressalta-se o já referido caso Chevron/Texaco -, ocasionando uma diminuição dos fundos produtivos presentes na sociedade (SEN, 2010, p. 168).

A observação das imprudências e dos limites não determinados de atuação dessas empresas pode evidenciar que, em determinadas circunstâncias, o auto privilégio e as pressôes para aumento do capital privado podem acarretar sérios danos

4 Registre-se, por oportuno, que "O surgimento da ética empresarial como campo de estudos está intimamente ligado à evoluçáo do sistema econômico, assim como às mudanças por que passaram as sociedades industriais no último século. Foram as transformaçóes (e excessos) do capitalismo que deram origem a esse tipo de questionamento ético, na medida em que as empresas privadas, transformadas em gigantescos conglomerados e multinacionais, começaram a dar mostras de um poder sem precedentes (ANDRIOFF; MCINTOSH, 2001; CARROLL; BUCHHOLTZ, 2000; KORTEN, 1995). Os conflitos relativos à questão ambiental, além das grandes reivindicaçóes sociais que emergiram nos anos 60 , também contribuíram para a formalização dos crescentes ataques e questionamentos vis-à-vis das empresas" (KREITLON, 2004, p. 3). 
e, portanto, ser totalmente contrárias aos interesses sociais (SEN, 2010, p. 168).

A responsabilidade das empresas transnacionais se sobressai aos direitos humanos e sociais, pois a impossibilidade de atividade irrestrita desses agentes promove instabilidade econômica, debilitando direitos econômicos e sociais características da globalização neoliberal -, que gera impactos nos direitos civis (ZUBIZARRETA, 2009, p. 246).

Os países periféricos, principalmente os perpassados pelas consequências de crises internacionais, não detêm poder político e jurídico para submeter esses novos atores transnacionais à sua regulação. Diante dessa situação, caberia ao Direito Comercial Global estabelecer parâmetros de atuação, tendo por escopo a supremacia dos direitos e interesses sociais, em face do atual cenário de supremacia dos interesses das transnacionais (ZUBIZARRETA, 2009, p. 671).

Diante do poder adquirido pelas transnacionais, os espaços onde elas atuam tornam-se ambientes propícios de subordinação, de desregulação do valor social do trabalho, e de mitigação da soberania. Além de contribuir significativamente para a degradaçáo ambiental, como bem referido nos parágrafos anteriores, a atividade desregrada dos novos atores transnacionais vem para privar a população local de seus direitos fundamentais garantidos nas constituiçóes de seus respectivos países, bem como tem violado a Declaração Universal dos Direitos Humanos.

Por todo o exposto neste tópico, abordar-se-ấo no seguinte os principais aspectos daquilo que se entende por sustentabilidade em seu viés social, especialmente os meios efetivos para sua implementaçáo na era da globalizaçáo e transnacionalização. Com especial ênfase, tratar-se-á do conteúdo do standard ISO 26.000, que fora elaborado justamente para servir como um norteador para os agentes privados respeitarem e promoverem a responsabilidade e sustentabilidade social na gestão do comércio transnacional.

\section{A promoção da sustentabilidade social: norma ISO 26.000}

As discussóes sobre o tema da sustentabilidade se desenvolvem a partir de diversas frentes que se tornam cada vez mais relevantes para resguardar os direitos civis neste período fortemente marcado pela globalizaçáo. A ideia de sustentabilidade, incialmente, fora fortemente associada como uma reposta para a crescente escassez de recursos, o que tem se mostrado ineficaz dentro de um contexto de constante interaçáo entre atores globais e locais, que requer o desenvolvimento de uma racionalidade mais ampla, tendo como norte a promoção da sustentabilidade ambiental, econômica e social (BOSSELMANN, 2015, p. 43). 
Por essa razão, tem-se que a racionalidade cartesiana proposta pelos modelos positivistas e demais concepçôes já não é mais capaz de dar conta da conjunção de fatores que precisam ser considerados para que seja possível construir uma noção de sustentabilidade coincidente com as demandas do século XXI. Simplesmente oferecer uma resposta, norteada pela razão matemática, não é suficiente, é necessário que sua complexidade seja entendida, considerando e contextualizando nossa realidade social (DIAS; AQUINO, 2019, p. 4).

Assim, o debate e o enfrentamento das questóes que envolvem a sustentabilidade contemporaneamente, devem ser fortemente embasados pela ideia de pluralidade, de modo a afastar qualquer tipo de compreensão reducionista ou que ignore locais de produção e formas de conhecimento considerados subalternos (DIAS; AQUINO, 2019, p. 4). Nesse sentido, estabelecem-se as críticas direcionadas àquelas correntes que colocam em igual patamar as ideias de sustentabilidade e de desenvolvimento sustentável -, sendo os dois conceitos frontalmente distintos.

A sustentabilidade deve ser considerada a matriz e orientaçáo de todas as formas de desenvolvimento humano, sendo pautada por uma racionalidade ecológica, diferentemente da ideia de desenvolvimento sustentável defendida pelo Relatório Brandtland, que optou por incluir conceitos ligados à ideia de desenvolvimento irrefreado, deixando de lado constataçôes científicas e de caráter político e, principalmente, econômico (BOSSELMANN, 2015, p. 45).

Assentado, portanto, que a sustentabilidade pauta o desenvolvimento, e náo o contrário, é mais do que relevante apontar o caráter multidimensional da sustentabilidade, ou seja, o princípio desta não pode ser lido de maneira única e imutável, pois o bem-estar que se deve buscar dentro da sociedade também é multidimensional (FREITAS, 2012, p. 57). Para concretizar essas perspectivas diferentes de bem-estar, é necessário cuidar do ambiental (dimensão ambiental), sem ofender o social (dimensão social), o econômico (dimensão econômica), o ético (dimensão ética) e o jurídico-político (dimensão jurídico-política).

Cada uma dessas diferentes dimensóes da sustentabilidade precisa necessariamente que as demais estejam em constante aperfeiçoamento e desenvolvimento para que possam alcançar seus objetivos; são princípios norteadores do Direito Constitucional e, também, valores a serem inseridos na centralidade da sociedade. Afinal, a dimensão social da sustentabilidade está ligada à construção de um modelo social que negue um crescimento desigual e iníquo (FREITAS, 2012, p. 58).

Por isso, sob a égide deste novo paradigma náo pode haver espaço para simplificaçóes e discriminaçóes, como de raça e gênero, entre outras. Neste sentido, ganham força as distinçóes que privilegiam os desfavorecidos, mediante a implementação de açóes positivas e compensaçóes que sejam capazes de sopesar as 
desigualdades em todos os campos sociais (FREITAS, 2012, p. 58).

Inseridos na dimensão social da sustentabilidade, estão os direitos fundamentais sociais, os quais reclamam as necessárias açôes para a universalização eficaz de seus desígnios, mediante o fomento a boas práticas de governança, unindo o público e o privado na promoção desses ideais (FREITAS, 2012, p. 59). A partir da adoção desse tipo de prática, a ideia de governança, atualmente inafastável da discussão dos problemas oriundos da globalização, pode tornar-se verdadeiramente sustentável.

Trabalha-se a ideia de que o melhor produto, no sentido da proteção ambiental, será considerado insustentável se não observar direitos e valores básicos, como por exemplo a dignidade do trabalhador (FREITAS, 2012, p. 59). É necessário que se promovam todos os meios para viabilizar um ambiente de trabalho que atente ao respeito à integridade física e mental deste.

Comprovadamente, as sociedades mais equitativas, não necessariamente as mais ricas, são as mais propensas a gerar e distribuir bem-estar. Em geral, a sustentabilidade em sua dimensão social tem características básicas, quais sejam: (a) incremento da equidade intra e intergeracional; (b) criação de condiçóes para o aumento das capacidades humanas, com educação de qualidade para o convívio social; e (c) engajamento na promoçáo do desenvolvimento que perdura e faz que a sociedade sobreviva, a longo prazo, com dignidade e respeito à dignidade dos cidadãos (FREITAS, 2012, p. 60).

Como anteriormente mencionado, a gerência dos problemas oriundos da globalização perpassa, necessariamente, pelo conjunto de açôes coordenadas em associação pelas forças públicas e privadas. A difusão das melhores práticas para a implementação da agenda de sustentabilidade social também está inserida nesse processo, que é verificável a partir da análise da ISO 26.000, concernente à responsabilidade social na atuação das empresas.

A partir das demandas constituídas pelas organizaçóes empresariais e pela sociedade civil como um todo, a ISO pretende organizar normas que facilitem o comércio, boas práticas de gestão e inovação tecnológica. Suas normas são adotadas integralmente por milhares de organizaçôes e são desenvolvidas por mais de três mil comitês técnicos, subcomitês e grupos de trabalho que, na totalidade, reúnem em torno de 50 mil especialistas em seus quadros (COSTA, 2011, p. 12).

A Organização Internacional de Normatização (ISO), agente responsável por traçar o referido indicador, foi criada ainda em 1946 por representantes de 25 países e desenvolve-se de tal modo que, atualmente, é composta por representantes de 163 países. Atualmente, a Organização Internacional de Normatizaçấo conta com um portfólio de 16.500 standards elaborados, os quais regulam desde especificaçóes 
de produtos e métodos de testes, até gerenciamento e responsabilidade social (BALZAROVA; CASTKA, 2012, p.267), como é o caso da ISO 26.000.

Os debates envolvendo a possibilidade da criação da norma ISO 26.000 foram iniciados em meados de 2001, ano em que a instituição solicitou ao seu comitê de política ao consumidor, uma avaliação acerca da viabilidade da construção de uma norma sobre responsabilidade social. Ao final de julho de 2002, o comitê recomendou a criação de uma norma nesses moldes, momento em que um grupo de trabalho envolvendo atores interessados foi criado para orientar a confecção final da norma (COSTA, 2011, p. 15).

A partir disso, uma série de encontros ao redor do mundo foram promovidos e liderados por esse grupo de trabalho, com apoio irrestrito da ISO, com a finalidade de discutir todos os vieses sobre a ideia de promover sustentavelmente a responsabilidade social globalmente. Ao final das discussóes, já no ano de 2010, as principais conclusôes dessas reuniōes foram unificadas e a norma ISO 26.000 foi formada (COSTA, 2011, p. 16).

O documento, promovido pela Organização Internacional de Normatização (ISO), traça consideraçôes e caminhos para a implementação de boas práticas de responsabilidade social no dia a dia das corporaçóes. Responsabilidade social nas empresas, a ISSO 26.000 visa encorajar a condução responsável dos negócios e a implementação de sistemas de accountability. O documento oferece para as corporaçóes um ponto de referência comum que responde às expectativas dos acionistas e implementa as práticas de responsabilidade com a sociedade civil (RASCHE, p. 504, 2011).

A Organização Internacional de Normatização (ISO) é uma federação global que reúne em seus quadros, órgáos de diversos países que são responsáveis por esses campos, com o objetivo de criar standards capazes de responder as demandas exigidas pelo mercado, facilitar o comércio, disseminar o conhecimento e as novas tecnologias (BALZAROVA; CASTKA, 2012, p.267).

A definição de responsabilidade social na ISO 26.000 é bastante sucinta e objetiva. Em consonância com o documento, a responsabilidade social consiste na responsabilidade de uma determinada organização pelos impactos e consequências de suas decisóes e atividades na sociedade e no meio ambiente, a partir de um comportamento ético e transparente que (a) contribua para a promoção da sustentabilidade, inclusive a saúde e o bem-estar social; (b) leve em conta os desejos das partes interessadas; (c) esteja em acordo com a legislação aplicável e seja consistente com as normas internacionais de comportamento; e (d) esteja inserida e praticada em toda a organização e suas relaçôes (COSTA, 2011, p. 22).

Outro pilar referencial que existe na norma em comente é o chamado 
princípio da precaução. Esse princípio tem como objetivo prevenir ameaças ou danos irreversíveis ao meio ambiente ou à saúde humana de modo geral, quando em situaçôes de incertezas sobre os reais efeitos de determinadas práticas ou decisōes a curto, médio e longo prazo. Um exemplo paradigmático da aplicação deste princípio está ligado à produção de alimentos transgênicos, dada a incerteza científica dos efeitos desses gêneros alimentícios no corpo humano, recomendase, por precaução, portanto, que esses não sejam massivamente produzidos e consumidos (COSTA, 2011, p. 26).

A norma passa a ideia de que a responsabilidade social está intimamente ligada ao conceito de sustentabilidade, e embora as vezes citados como sinônimos, são distintos. A sustentabilidade está subdividida em três dimensôes distintas, quais sejam: social, ambiental e econômica. Esses três aspectos são complementares, e o sucesso em suas articulaçôes traz como consequência a criação de um modelo baseado nas expectativas da sociedade como um todo. Já a responsabilidade social está restrita às organizaçóes e a sua esfera de influência, bem como os compromissos que as organizaçóes devem selar para com o bem-estar da sociedade e a manutenção do meio ambiente (COSTA, 2011, p. 27).

Considerando a importância dos expedientes de governança, associando tanto os setores públicos como os privados na luta para a efetivação da ideia de sustentabilidade e na garantia de direitos fundamentais, fica evidenciada a importância de normas e standards nos moldes da ISO 26.000. Ao criar esse poder de tipo soft, a promoção da sustentabilidade, principalmente em sua dimensão social, torna-se mais factível, na medida em que a sociedade define para si própria, comportamentos de acordo com tal finalidade.

Por essa razão, o debate acerca dos meios capazes de fazer o caminho para a construção de um ambiente propício à sustentabilidade sai enriquecido quando feito a partir da aplicaçáo de normas standards, como é o caso da ISO 26.000. O reconhecimento dos expedientes de governança como uma das formas de resolução de problemas da sociedade em sua matriz global e transnacional é indicativo da possibilidade da utilização das normas ao estilo ISO como propulsoras da sustentabilidade em escala global.

\section{Conclusáo}

Portanto, os processos de globalização e transnacionalização alteraram profundamente a face do poder estatal, principalmente a partir de 1945. Com a aceleração desses movimentos, o Estado foi paulatinamente perdendo seu lugar absoluto de poder, vendo-se forçado a dividir determinadas funções anteriormente 
reservadas somente a seus desígnios, com atores de matriz público-privada ou inteiramente públicos, como é o caso da produção normativa.

Verifica-se que essa transferência ou compartilhamento de poder do Estado para com estas instituiçôes transnacionais é, acima de tudo, problemática, na medida em que, em meio a este atrito, novas questóes sociais de extrema relevância são constituídas. A atuação dessas organizaçôes transnacionais em larga escala e com cada vez mais autonomia, tronou-se problemático na medida em que, em um número significativo de casos, entrou em atrito com direitos fundamentais de populaçôes locais, como demonstrado na descrição do caso envolvendo a empresa Chevron e o Estado do Equador.

Outro debate de fundamental importância do período em que vivemos gira em torno das questóes concernentes à sustentabilidade e suas dimensóes e, em especial, sua dimensão social. Nesse particular, cada vez mais fica evidente a necessidade de se intensificar a promoção de políticas que incentivem a disseminação da sustentabilidade, de modo que os impactos do crescimento econômico sejam minimizados ao máximo em todas as esferas da sociedade, não apenas nas questôes ambientais.

Nesse passo, ao constatar a impossibilidade do Estado dar conta da tarefa de disseminar boas práticas, visando a manutenção da sustentabilidade social por conta própria, a ideia é fortalecer os expedientes de governança, unindo forças de agentes públicos e privados, para adimplir nessa tarefa. Exemplo desse tipo de iniciativa é a norma ISO 26.000, elaborada para direcionar a atuação das organizaçôes transnacionais ao encontro da sustentabilidade e da responsabilidade social, de modo a evitar desastres sociais como ocorrido no Equador quando da operação da Chevron naquele país.

Por fim, conclui-se que a hipótese de pesquisa suscitada revelou-se verdadeira, na medida em que os expedientes de governança, tal qual as normas standards, a exemplo da ISO 26.000, são capazes de auxiliar a disseminação da sustentabilidade social em nível global. Isso se deve ao fato de as normas de matriz público privada, ao estio soft, terem a possibilidade de alcance maior do que aquelas que estâo nas máos dos Estados e podem, inclusive, ser aplicadas independentemente do local onde determinada empresa esteja atuando. 


\section{Referências}

ARNAUD, A.-J. Governar sem fronteiras: entre globalização e pós-globalização. Rio de Janeiro: Lumen Juris, 2007.

BALZAROVA, M. A.; CASTKA, P. Stakeholders' Influence and Contribution to Social Standards Development: The Case of Multiple Stakeholder Approach to ISO 26000 Development. Journal of Business Ethics, [s.l.], v. 111, n. 2, p. 265-279, 28 jan. 2012.

BRASIL, D. R. Empresas transnacionais sob o império da nova ordem mundial e sua integração no Direito Internacional. Revista dos Tribunais, Belo Horizonte, v. 792, p. 35-62, out. 2001. Disponível em: http://revistadostribunais.com.br/ $\mathrm{maf} / \mathrm{app} / \mathrm{resultList} / \mathrm{document}$ ? \&src=rl\&srguid=i0ad6007900000157475f9c8cfdd396a0\&docguid=Ie3702fd0f25011 dfab6f010000000000\&hitguid=Ie3702fd0f $25011 \mathrm{dfab} 6 f 010000000000 \&$ spos $=4 \&$ epos $=4 \& \mathrm{td}=908 \&$ context $=18 \& \mathrm{crum}-$ b-action=append $\&$ crumb-label=Documento \&isDocFG=false \&isFromMultiSumm;=\&startChunk=1\&endChunk=1. Acesso em: 1 nov. 2019.

BOSSELMANN, K. O principio da sustentabilidade: transformando direito e governança. São Paulo: Revista dos Tribunais, 2015.

COSTA, H. ISO 26.000 Norma Internacional de Responsabilidade Social: um guia para entendê-la melhor. São Paulo: Instituto Observatório Social, 2011.

CRUZ, P. M.; OLIVIERO, M. Fundamentos de Direito Transnacional. In: ROSA, A. M.; STAFFEN, M. R. Direito global: transnacionalidade e globalização jurídica. Itajaí: Univali, 2013.

JESSUP, P. C. Transnational Law. New Haven: Yale University Press, 1956.

FREITAS, J. Sustentabilidade: direito ao futuro. 2. ed. Belo Horizonte: Fórum, 2012.

DIAS, F. V.; AQUINO, S. R. F. Sustentabilidade social: reflexões em busca de uma sociedade mais justa. Revista Jurídica (furb), Blumenau, v. 50, n. 23, p. 1-20, abr. 2019 .

KIMERLING, J. Lessons from The Chevron Ecuador Litigation: The Proposed Intervenor's Perspective. Stanford Journal of Complex Litigation, Stanford, v. 12, p. 241-294, 2013.

KREITLON, M. P. A ética nas relações entre empresas e sociedade: fundamentos teóricos da responsabilidade social empresarial. XXVIII ENCONTRO DA 
ANPAD - ENANPAD, 28., 2004, Curitiba. Anais [...]. Maringá: Anpad, 2004. Disponível em: http://www.anpad.org.br/admin/pdf/enanpad2004-gsa-2651. pdf. Acesso em: 10 dez. 2019.

MUECKENBERGER, U.; JASTRAM, S. Transnational norm-building networks and the legitimacy of corporate social responsibility. Journal of Business Ethics, v. 97, n. 2, p. 223-239, 2010.

OLIVIERO, M.; STAFFEN, M. R. Il Diritto Globale: giustizia e democrazia oltre lo stato (Sabino Cassese). Sequência: Estudos Jurídicos e Políticos, Florianópolis, v. 34, n. 66, p. 357-360, jul. 2013. Disponível em: https://periodicos.ufsc.br/index.php/sequencia/article/view/21777055.2013v34n66p357/25226. Acesso em: 30 ago. 2016.

RADU, L. Transnational companies and their role in globalization. Lex ET Scientia International Journal, v. 16, n. 1, p. 397-406, 2009.

RASCHE, A. Collaborative governance 2.0. Corporate Governance, v. 10, n. 4, 2010.

SEN, A. Desenvolvimento como liberdade. São Paulo: Companhia da Letras, 2010.

STAFFEN, M. R. Hegemonia e Direito Transnacional? Novos Estudos Jurídicos (Online), Itajaí, v. 20, p. 1166-1187, 2015.

STAFFEN, M. R. Interfaces do Direito Global. Rio de Janeiro: Lumen Juris, 2015.

STRINGARI, A. K. A eficiência como princípio orientador da atividade admistrativa. Revista Bonijuris, Curitiba, v. 562, p. 51-57, set. 2010. Disponível em: https://app.vlex.com/\#WW/vid/235458761. Acesso em: 4 set. 2017.

WHYTOCK, C. A. The Chevron-Ecuador case: three dimensions of complexity in transnational dispute resolution. Proceedings of The AsilAnnual Meeting, Oxford, v. 106, p. 425-428, 2012.

ZUBIZARRETA, J. H. Las empresas transnacionales frente a los derechos humanos: historia de una asimetría normativa - de la responsabilidad social corporativa a las redes contrahegemónicas transnacionales. Bilbao: Hegoa; Madrid: OMAL, 2009. 